\title{
THE RISE OF FRACTIONAL SCHOLARSHIP
}

Samuel Arbesman

Ewing Marion Kauffman Foundation

$$
\begin{gathered}
\text { Jon Wilkins } \\
\text { Ronin Institute }
\end{gathered}
$$

May 2012

Ewing Marion

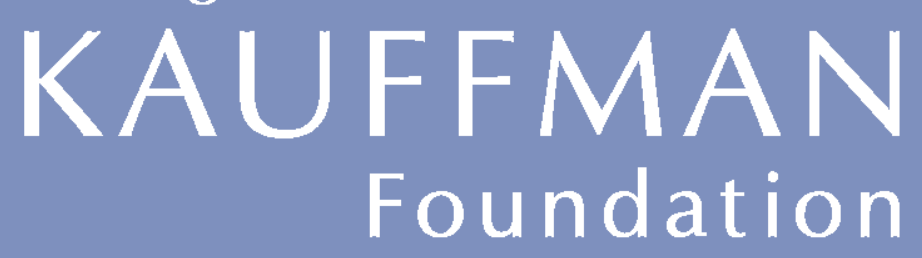




\title{
THE RISE OF FRACTIONAL SCHOLARSHIP
}

\author{
Samuel Arbesman \\ Ewing Marion Kauffman Foundation \\ Jon Wilkins \\ Ronin Institute
}

May 2012

\section{Ewing Marion \\ KAUFFMAN \\ Foundation}

(c) 2012 by the Ewing Marion Kauffman Foundation. All rights reserved. 
At the end of World War II, Vannevar Bush, with a single document titled Sciencethe Endless Frontier, set up the current scientific establishment and its governmental funding structure. The document laid the groundwork for such funding organizations as the National Science Foundation, the building of large academic laboratories funded by federal money, and the education of large number of American students in the basic sciences. This placed the research university at the forefront of innovation in science and technology (military and governmental labs had done such research during World War II) and allowed for the massive production and employment of scientists.

The research university model has worked well for decades, and continues to be central to the creation and preservation of knowledge. In fact, this centrality can make it easy to forget that there are many career paths open to PhDs. In some fields, like computer science or the life sciences, many newly minted PhDs leave academia for jobs in industry. In other fields, people who leave academia find careers in science writing or consulting, or move on to jobs that don't take direct advantage of the skills and knowledge they have acquired in graduate school.

But what about people who want to continue to pursue scholarly research? After all, the pursuit of knowledge is one of the reasons why many people go to graduate school in the first place. Most careers in industry involve more directed research, and science writers and consultants may interact with academic scholars, but do not typically engage in research of their own. It is commonly perceived that, if you want to do primary research, where you control the research questions, your major option is traditional academia.

However, the canonical academic career, heading up a group of graduate students and postdocs at a major university, is not an option for most would-be scholars. American universities produce far more PhDs than there are jobs of this sort. ${ }^{1}$ For example, between 2005 and 2009, more than 100,000 doctoral degrees were granted, while only 16,000 faculty positions were created. ${ }^{2}$ A simple back-of-theenvelope calculation shows that within computer science, the top ten universities

\footnotetext{
${ }^{1}$ Benderly, B. L. (2010). The Real Science Gap. Miller-McCune. Retrieved from http://www.miller-mccune.com/science/the-real-science-gap-16191/.

2 The Economist. (2010). Doctoral degrees: The disposable academic. The Economist (16 December). Retrieved from http://www.economist.com/node/17723223. Note that many of these degrees are granted to foreign-born students, who may not wish to find employment in the United States.
} 
generate enough PhDs to fill every computer science faculty position within the United States. ${ }^{3}$

For many, a full-time faculty position is not even the ideal goal. There are many possible reasons for this. For some, health or family considerations make the 70- to 80 -hour work week of most research academics untenable. For others, family considerations impose geographic restrictions that make it impossible to compete in the academic job market. A recent survey of chemistry PhD students in the United Kingdom found that the vast majority did not want to go into academia. Women, in particular, found the university path unappealing, citing the all-consuming and competitive nature of academic careers. ${ }^{4}$

For others still, their scholarship is of high quality, but does not fit neatly into one of the preexisting academic departments, therefore rendering them unemployable within a traditional university framework. Whatever their reasons, the result is that there currently exists a vast, untapped resource of talent made up of individuals who wish to pursue scholarship but are unable to.

\section{Fractional Scholarship}

Work at the Kauffman Foundation has demonstrated that, in addition to large numbers of individuals continuing to start companies and engage in entrepreneurship, there is a growing trend in what is being termed fractional entrepreneurship, the use of a portion of one's time to run a company. ${ }^{5}$ Clay Shirky, in Cognitive Surplus, has explored the phenomenon that our cognitive spare time is increasingly being used constructively, from the creation of Wikipedia, to medical data at PatientsLikeMe. ${ }^{6}$ Similarly, fractional entrepreneurs use this cognitive surplus

\footnotetext{
${ }^{3}$ Clauset, Aaron. (January 13, 2012). A crisis in higher education? Retrieved from http://www.cs.unm.edu/ aaron/blog/archives/2012/01/a_crisis_in_hig.htm. ${ }^{4}$ Royal Society of Chemistry (2008). The chemistry PhD: the impact on women's retention. Retrieved from http://www.theukrc.org/files/useruploads/files/the_chemistry_phdwomensretention_tc m18-139215.pdf.

${ }^{5}$ Grant, Alexis (March 30, 2011). And on the Side, I'm an Entrepreneur. U.S. News and World Report. Retreived from http://money.usnews.com/money/careers/articles/2011/03/30/and-on-the-side-im-anentrepreneur.

${ }^{6}$ Shirky, C. (2010). Cognitive Surplus: Creativity and Generosity in a Connected Age. Penguin Press.
} 
to start part-time businesses, selling work online at such websites as Etsy or oDesk. It is time we begin to adopt this model for the world of scholarship and research.

Fractional scholarship, and the harnessing of unused scholarly expertise, is akin to the distributed computing projects, like SETI@home. SETI@home, like many other initiatives of this type, recognizes that most computers remain idle for much of their lifetime, and that these spare computational cycles can be harnessed to solve difficult problems, from combing the sky to detect signals from extraterrestrials, to calculating how large proteins fold. Fractional scholarship would harness under-used scholars, rather than CPUs.

In fact, fractional scholarship already occurs on a smaller, more ad-hoc level, in the area of citizen science and crowdsourcing. This area allows large tasks to be made more tractable through the division of a problem and the distribution of its parts to the untapped resource of individual spare time. For example, Galaxy Zoo harnesses individuals interested in the categorization of galaxies, through the viewing of astronomical images.

Certain scientific problems already have begun to be solved through citizen science and a distributed approach to scholarship. The Zooniverse Project, which is the umbrella for all projects that grew out of Galazy Zoo, has found new planets outside the solar system, discovered entirely novel astronomical objects, and authored numerous scientific publications. A mathematical proof has even been achieved through a collaborative, fractional approach to scholarship. ${ }^{7}$

Unfortunately, not all science can be done in such a simple distributed fashion, with small tasks farmed out to a group of non-experts. A better approach to harnessing the skills of underemployed scholars would be to embrace a bottom-up model, with the scholars themselves identifying and defining the questions that are most important and interesting. What is needed now are new mechanisms to facilitate fractional scholarship and engage the thousands of would-be scholars out there.

\section{An Institution to Harness Fractional Scholarship}

While the concept of fractional scholarship is an exciting one, it often is difficult, if not impossible, for an individual to participate in fractional scholarship on one's own. Due to issues such as the lack of an affiliation to facilitate publication or grant applications, or even journal access issues, it is hard to be a lone fractional scholar.

\footnotetext{
${ }^{7}$ Nielsen, Michael. Reinventing Discovery: The New Era of Networked Science. 2012. Princeton University Press.
} 
Therefore, for fractional scholarship to be feasible, an institution must exist to aggregate certain functions and resources that facilitate such research. Such an institution would provide an institutional affiliation, a community, help for researchers to apply for grants and publish articles, and much more, while still ensuring independence and the ability to conduct research on one's own terms.

Grant support and management could be aggregated, with such an institution helping fractional scholars to identify funding opportunities, assemble application materials, and even manage grants.

In addition, such an institution could help aggregate and solicit funding directly from the public, working according to a crowdfunding mechanism. There are emerging projects specifically designed to allow for such crowd-based microfunding of scientific research. While common in the art and design worlds ${ }^{8}$, such funding is newer to scholarship. However, it does exist. For example, SciFlies acts as a clearinghouse for the funding of research projects that have been reviewed by experts. ${ }^{9}$ These novel funding structures are particularly well suited to fractional research.

Furthermore, such an institution would be able to create a research community for fractional scholars. It would be too easy for fractional scholars to become isolated, so an institution could create forums, both online and in-person, for fractional scholars to come together to share ideas and discuss research strategies.

In addition to aggregating the above functions, there are other benefits. Unlike many full-time principal investigators who only spend a portion of their time actually engaged in scholarship, scholars affiliated with an institution designed to foster fractional entrepreneurship would spend all of their funded time on research, operating at a far lower cost than a typical university professor.

\footnotetext{
${ }^{8}$ See, for example, Kickstarter.com.

${ }^{9}$ Located at sciflies.org. For more information, see the following articles:

Fellet, Melissae (December 19, 2011). Crowdfunding science: Give a gift to research. New Scientist. Retrieved from http://www.newscientist.com/blogs/culturelab/2011/12/give-a-gift-to-research.html; Lin, Thomas (July 11, 2011). Scientists Turn to Crowds on the Web to Finance Their Projects. New York Times. Retrieved from http://www.nytimes.com/2011/07/12/science/12crowd.html?_r=1\&pagewanted=all; Giles, Jim (January 18, 2012). Finding philanthropy: Like it? Pay for it. Nature. Retrieved from http://www.nature.com/news/finding-philanthropy-like-it-pay-for-it1.9815 .
} 


\section{Summary}

When people are doing something they are passionate about, they work harder and produce a better product. Thus, underemployed scholars represent, in some sense, a good that is currently trading well below its actual value. Of course, in the course of their primary employment, many of these individuals can and do provide value to the economy outside of traditional scholarship. However, by providing a mechanism for those who wish to conduct research, we can allow these people to engage in their passions while growing the base of scholarly knowledge, which, in turn, has the potential to create further economic growth.

By creating an institution devoted to fractional scholarship, we will harness the skills and talents of thousands of underemployed researchers. At the same time, traditional academia will be aided in the creation of a new, attractive career path for people with graduate degrees.

Freed from the strictures of traditional academia, fractional scholarship will be able to leap ahead of the departmental structures and artificial boundaries to collaboration too often found in universities. Fractional scholars, drawing on more varied life experiences than those steeped within the ivory tower, will not simply be scratching a research itch. They will be performing creative research, some of which could not even be done within traditional academia, and, at the same time, acting as a newfound scholarly resource for our nation. 